Preprint disclaimer: This manuscript has not yet been peer-reviewed and will almost certainly be revised before publication. 
An Integrative Model of Teacher Education:

Educating Teaching Knowledge and Social, Cognitive and Affective Skills

\author{
Matthew J. Hirshberg \\ University of Wisconsin Madison, Center for Healthy Minds and Department of Educational \\ Psychology, Madison, Wisconsin, USA
}

Correspondence concerning this article should be addressed to:

Matthew J. Hirshberg

https://orcid.org/0000-0001-9070-1270

E-mail: hirshberg@wisc.edu

\title{
Funding
}

This research was supported by an Institute of Educational Sciences grant (R305A140479), a Mind \& Life Institute award (2014-Varela-Hirshberg), a Trust for the Meditation Process award (15-08), a National Academy of Education / Spencer foundation Postdoctoral Fellowship, and by generous individual donations to the Center for Healthy Minds.

\section{Conflicts of interest/Competing interests}

The author reports no conflicts of interest.

\section{Acknowledgements}

I'd like to thank Evan Moss, M. Elizabeth Graue, Craig Hase, Leandro Chernicoff and John Dunne for their comments on earlier drafts of this manuscript. 


\begin{abstract}
Teacher quality explains more variance in student outcomes than any other school-based factor. An effective teaching corps is vital in order to improve educational outcomes, but effective teaching is complex. Effective teachers adaptively regulate the classroom environment, promoting safe, organized learning contexts that promote student engagement and are sensitive to the academic, social and emotional needs of students. Research has illuminated teaching behaviors that optimize student engagement and learning, but little theoretical or empirical work has explicated the antecedents that allow for these behaviors to emerge. Without identifying and then educating these antecedents, teachers can learn about effective practices without being able to enact them. In this review, core antecedent skills involved in teaching are identified, operationalized and disaggregated from teaching knowledge and from the teaching behaviors that are recognized as effective forms of practice. A novel developmental model for teacher education that marries the cultivation of knowledge with skills is proposed.
\end{abstract}

Keywords: teacher education, teacher effectiveness, knowledge, skills, mindfulness 


\section{An Integrative Model of Teacher Education:}

Educating Teaching Knowledge and Social, Cognitive and Affective Skills

There are around 80 million teachers engaged in educating over a billion primary and secondary school students worldwide (Roser, 2020). Academic learning has long been focal in this endeavor. Recognition of the importance of educating social-emotional and other notspecifically academic skills continues to expand (Schonert-Reichl, 2019). As a result, teachers are expected to educate skills and knowledge, adding further complexity to the already considerable challenge of equitably educating all children. The stakes in this pursuit are difficult to exaggerate - educating the skills and knowledge required in the future will affect social and economic well-being on nation-state scales (Knudsen, Heckman, Cameron \& Shonkoff, 2006).

Effective teaching is complex, involving more than pedagogical and content area knowledge (Shulman, 1986). Effective teachers adaptively regulate the classroom environment, promoting a safe, organized learning space that promotes engagement while being sensitive to the social and emotional needs of students (Pianta \& Hamre, 2009). Regulating a learning environment and the complexities of the students within it begins with the ability to monitor and regulate one's self (Cheng \& Zamarro, 2018; Klusmann, Kunter, Trautwein, Ludtke, \& Baumert, 2008). A teacher who reacts with anger to students will struggle to establish an effective social context for learning (Yoon, 2002; Sutton, Mudrey-Camino, \& Knight, 2009), no matter how deep their content knowledge or how well-devised their lesson planning. Despite understanding that learning occurs in a social context and teacher behaviors are central to determining the functioning of that context (Putnam \& Borko, 2000), little theoretical work has operationalized the antecedents that teachers need in order to behave in ways that promote learning.

In this review I synthesize research on teaching, teacher effectiveness, and expertise to 
propose a new framework for understanding the constituents of effective teaching. Teachingrelevant knowledge, in all of its many operationalized forms, has been the dominant focus of teacher education and teacher credentialing regimens (Grossman \& McDonald, 2008). But knowledge represents only half of the primary antecedents involved in learning to teach. An array of social, cognitive and affective skills are equally crucial. I contend that when adequate knowledge is coupled with sufficient skill, cycles of learning, practice and reflection become meaningful, leading to developed automaticity of the core practices of teaching which then makes adaptive expertise possible (Darling-Hammond \& Bransford, 2005).

Identifying skills as an important aspect of learning to teach is not novel. Some knowledge competencies capture elements of skills as I will define them. Researchers have also proposed constructs that overlap to varying degrees with the forthcoming presentation of skills (e.g., Pelligrino \& Hilton, 2012; Schonert-Reichl, 2019). Despite scholars often noting a role for skills, the construct has not yet been adequately operationalized. Frequently, skills are conflated as knowledge, obscuring the unique contributions that knowledge and skills make to the process of learning to teach. In turn, the fact that they must be educated in different ways has been hidden. As a consequence, teacher education has evolved around the development (and assessment) of knowledge, even when skills are rhetorically centralized. Solving perhaps the most vexing challenge identified by teacher education scholars - the problem of enactment, or the gap between what teachers know to do and are actually able to do (Kennedy, 1999; Kennedy, 2016) - depends on the implementation of systematic skills education within teacher education.

\section{An integrative model for teacher education}

The Integrative Model of Teacher Education (IM) is a falsifiable developmental model of learning to teach that identifies teaching-relevant knowledge and social, cognitive and affective 
skills as the principle antecedents of learning to teach. When sufficient knowledge and skills learning has occurred, the cycles of learning, practice and reflection already embedded within quality teacher education (pre- or in-service) can be harnessed into meaningful growth, culminating in automaticity of the core practices of teaching. The basis of effective teaching and the standard for an ambitious teacher education agenda, automaticity of core practices allows limited cognitive and emotional resources to be allocated to the complex, non-routine and highly adaptive behaviors that define expert teachers. Integrative teacher education is a paradigmatic shift toward a teacher education that systematically educates teaching-relevant knowledge and social, cognitive and affective skills so that cycles of learning, practice and reflection can be harnessed to develop automaticity and make expert teaching possible.

Figure 1. An Integrative Model of Teacher Education Integrative teacher education

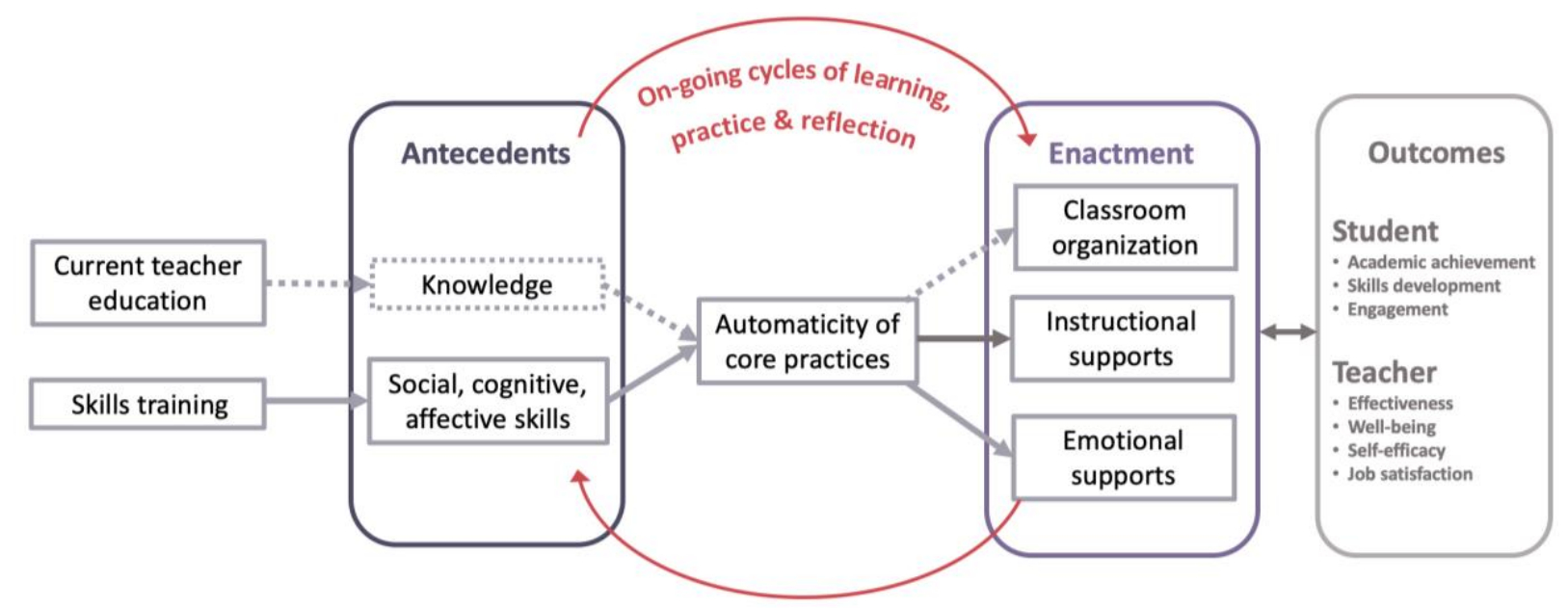

Fig. 1 Dashed arrows represent the enactment domain that knowledge is hypothesized to exert the greatest indirect effects on via automaticity of core practices. Solid grey arrows represent the enactment domain that skills are hypothesized to exert the greatest indirect effects on through automaticity of core practices. Solid dark grey arrows represent the enactment domain that skills and knowledge are hypothesized to contribute evenly indirect effects on through automaticity of core practices. 


\section{Defining Integrative Model Constructs}

\section{Teaching Knowledge}

Teaching-relevant knowledge competencies have been explored in great detail in teacher education scholarship. The first American teacher education schools, normal schools, were chartered with the understanding that essential teacher knowledge was multifaceted. Teachers were thought to require subject matter knowledge, of effective strategies for organizing and communicating that content knowledge (i.e., pedagogical knowledge), and of student development and learning processes (Labaree, 2008; Wright, 1930). Shulman (1986) shaped decades of subsequent teacher education research when he expanded instrumental forms of teaching knowledge to include pedagogical content knowledge (PCK). PCK can be distilled into three knowledge constituents: explanatory knowledge; knowledge of students thinking or learning approach in a specific content-area; and knowledge of the tasks that are required for competence in a content area (Baumert \& Kunter, 2013; Shulman, 1986). Later scholarship identified organizational knowledge or knowledge of learning contexts, knowledge of the purposes and ends of education, knowledge of student assessments, organizational knowledge (i.e., of the systems and structures of education), and counseling knowledge or knowledge about how to communicate aspects of teaching to the public as additional knowledge domains of import (Baumert \& Kunter, 2013; Shulman, 1987).

In the IM, knowledge competencies represent one of the two primary antecedents of learning to teach and half of the core content of integrative teacher education. Because knowledge competencies are already well represented in the teacher education literature, I do not provide extensive explication of them or their importance to teaching. Knowledge competencies are diverse, but can be characterized as a type of knowing colloquially described as knowing 
about something, termed declarative knowledge in cognitive psychology (Squire, 1992).

\section{Skills}

In contrast to knowing about something, skill is defined as the ability to do something well. In the nomenclature of cognitive psychology, this form of knowledge is described as procedural (Squire, 1992). Of critical importance, declarative knowledge and skill are dissociable at behavioral and neural levels of analysis, relying on some overlapping but also discrete neural substrates (Eichenbaum, 2000; Squire, 1992).

To make apparent the distinction between knowledge and skill, reflect on the following; would you endorse a law that allowed adolescents to drive a car after being told how to drive but never having actually practiced driving? Most with skill in driving would answer no. Similarly, no parent expects their child to be able to ride a bike after telling them to hold onto the handle bars, balance and peddle; declarative knowledge of biking's component processes (e.g., steer with the handle bars, peddle, brake) help orient a new rider, but to develop skill in riding the child must try to balance, peddle and brake, again and again. Once sufficient skill in the basic procedures of riding are attained, these skills become effortless and automatic, allowing the child to explore skid breaking, no hands riding and other advanced techniques. Teaching is infinitely more complex than learning to ride a bike but learning to ride a bike is a useful analogy of the contributions of knowledge and skills to learning to teach.

In order for the IM to be falsifiable, model constructs must be operationalized such that they are empirically interrogatable. To this end, I operationalize the skills construct according to the following parameters:

1. Evidence for learnability.

2. Measurability. 
3. Differentiability from declarative knowledge.

4. Differentiability from behavior.

5. Based on performance not perception or belief.

6. Domain-general.

\section{Skills are Learnable}

Skills are by definition abilities that can be learned through practice and are necessary antecedents to expertise (Duckworth \& Yeager, 2015; Goleman \& Davidson, 2017; Kunter, Klusmann, Richter, Voss, \& Hachfield, 2013). If the skills I will argue are instrumental to learning to teach were not learnable, but predetermined and fixed, teacher education scholars would be forced to conclude that some individuals could never develop into effective teachers. Rather than a model of learning to teach, the IM would provide a framework for screening teacher applicants. Understanding more about the strengths and weaknesses of future teachers' skill is advisable, but the IM assumes that provided the right motivation (Janssen, Grossman, \& Westbroek, 2015), learning to teach is possible because teaching-relevant skills (and knowledge) can be educated.

\section{Measurability}

The second criterion in defining a skill is that it can be measured. Absent a measure that produces valid and reliable scores, it is impossible to estimate a skill's relationship to effective teaching. I therefore limit discussion to skills for which a measure exists.

\section{Skills are Different From Knowledge}

Knowledge about riding a bike does not determine skill in riding a bike. Skill in riding does not necessitate knowledge about bikes. Many people can ride a bike but don't know how to fix one. Properly differentiating skills from knowledge is important because, as I will explore in 
detail later, different educational affordances, pedagogies and methods are required to educate them. History suggests that when knowledge and skills are not appropriately defined or when conflated, structures better suited to declarative knowledge development dominate, as is currently the case (Grossman \& McDonald, 2008; US DOE, 2014). This is not a surprise. Pedagogies and assessments of declarative knowledge are often more straightforward; pedagogies and assessments of skill are less ubiquitous (Duckworth \& Yeager, 2015).

\section{Skills are Different Than Behavior}

Skills are not behaviors even though it may only be through a behavior that a skill becomes observable. Behaviors, on the other hand, are by definition observable. How do we know one guitar player has skill and another does not? Both may enact the same behaviors and routines. For instance, both strum and finger pick. We infer skill not through the observable behavior but instead through its result or quality. Skill is present when the behavior of strumming produces a beautiful sound. In contrast, when the behavior of strumming produces noise, we deduce a lack of skill. Even when the behavior enacted is the same; the result can profoundly differ. Skill determines the result.

Teaching is similar. For example, a quiet classroom is not indicative of teacher skill in classroom management. The teacher walking one quiet room may be exploiting student fear whereas the teacher walking in another quiet room may be observing students and offering concise feedback to promote learning. Students in the first classroom, although quiet, might be lost in thought or disengaged whereas students in the other are engaged in independent, focused learning. Teacher skill can be deduced from the quality of the classroom and from students, not necessarily the observable behaviors of the teacher.

The consequences of making behaviors the focal point of teacher education is illustrated 
by early 20 th century research in which scholars attempted to codify the specific behaviors employed by effective teachers so that teacher education could then replicate them in trainees (e.g., Barr, 1929; Charters and Waples, 1929; Zeichner, 2012). The logic supporting this research agenda was appealing. If effective teaching behaviors could be codifed and future teachers trained to replicate them, the inevitable result would be reliably effective teachers. Why then did these attempts fail?

They failed because the focus on replicable behaviors produced overly prescriptive compendiums of behaviors (McDonald, Kazemi, \& Kavanagh, 2013) that promoted ambiguous constructs of effective teaching, allowing for disparate and even contradictory interpretations (Grossman \& McDonald, 2008; Zeichner, 2012). As a result, teacher education scholars came to coalesce around the understanding that "although teachers could be trained to produce almost any classroom behavior, these were 'empty techniques' because they failed to account for the many decisions teachers had to make and the knowledge they needed to decide wisely" (Cochran-Smith \& Power, 2010, p.12).

Contemporary scholars have deftly balanced the continued aversion to behaviorist conceptions of teaching with the widespread consensus that some behaviors are more effective than others and it is not only possible but indeed important to characterize these differences (Ball Payne, \& Hill, 2009; McDonald et al., 2013; Pianta \& Hamre, 2009). Identifying the core practices of teaching is an important aim of practice-based teacher education proponents. Among these scholars, the term skill is widely used. However, skill in this context does not refer to a set of antecedent competencies active when learning to enact or enacting effective practices but instead as a description of one who regularly enacts effective practice (Janssen et al., 2015). That is, one who regularly enacts effective practices has skill in enactment, or as Forzani (2014) 
described it "skill at... particular, well-specified practices" (Peercy \& Troyan, 2017). The term professional competence has been used similarly (Kunter et al., 2013).

The distinction I am drawing between the present operationalization of skills and the term's use elsewhere is subtle but important. In contending that skills are antecedent to learning to teach and therefore to enactment of effective teaching behaviors, I am also arguing that skills exist independent of those behaviors. In theory an individual could possess high levels of social, cognitive and affective skill and fail to learn to become an effective teacher. Lack of motivation to improve is one possible explanation. Lack of adequate teaching-relevant knowledge - the other focal point of integrative teacher education - is another. But it is also possible that an individual who possesses teaching-relevant skills, knowledge and the motivation to improve does not learn to be effective. This last scenario points to ineffectual pedagogies or educational structures in the process of educating teachers.

Pedagogies of enactment, approximations of practice, and decomposition, recomposition and rehearsal frameworks all speak to the need to break down the complexity of teaching into discrete chunks that can be more easily learned, practiced and ultimately "recomposed" in the full complexity of the classroom (Grossman, Hammerness, \& McDonald, 2009; Grossman \& McDonald, 2008; Janssen et al., 2015). Collectively, proponents of these approaches endeavor to innovate methods that result in higher levels of skill in practice. Such methods are entirely consistent with and necessary for the instantiation of an effective integrative teacher education. However, skills education as defined in integrative teacher education has a different target. Using Janssen et al.'s (2015) language of modularity in complex systems, skills here represent a "lower" level component of learning to teach upon which skill in practice is dependent. Skill in practice is defined by the probability that an effective teaching behavior is enacted. Levels of 
skill and knowledge determine that probability.

\section{Based on Performance Not Perception or Belief}

Self-perceptions or belief structures meet most of the criteria set forth for skills. They differ is one crucial aspect; self-perceptions and belief structures can become disconnected from performance. For example, self-efficacy is the degree to which one perceives themselves being capable of managing life demands. In the context of teaching, self-efficacy is the extent to which one believes they are capable of the core practices of teaching. The phenomenon has been extensively studied in teacher education research (Friedman \& Kass, 2002; Zee \& Koomen, 2016). On average, higher teacher self-efficacy is correlated with lower stress and burnout, better classroom management behaviors, greater well-being, and enhanced student academic adjustment (Zee \& Koomen, 2016).

Yet a teacher can experience high self-efficacy while being ineffective and possessing low social, cognitive and affective skill. In fact, lower levels of certain skills may be associated with higher self-efficacy because absent those skills, the ability to introspect and accurately appraise the effects of one's actions in the world are curtailed. It is possible then that at the same time that high self-efficacy may buffer against experiences of stress, it may also impede learning to teach. Indeed, higher student self-efficacy has been found to negatively correlate with motivation and achievement within student even while the average between student relationship was as expected positive (Vancouver \& Kendall, 2006). Research on expertise has also failed to find an association between perceived expertise and performance (Ericsson, 2017). Although accurate self-efficacy beliefs and confidence in one's ability to learn are desirable and may moderate the relationship between skills, knowledge and learning to teach, according to the IM, self-efficacy does not function as a necessary antecedent and therefore is not a skill. 


\section{Domain-General}

Domain-general refers to the fact that the same skill is applied across a variety of life demands. Social, cognitive and affective skills are associated with desirable outcomes in a wide array of professional and personal pursuits (Almlund et al., 2011; Knudsen et al., 2006). For example, the ability to focus attention is important across contexts. An athlete must filter out information irrelevant to their goal (e.g., fatigue). Teachers too must filter out irrelevant information so that they can focus on a desired stimulus (e.g., pedagogy). The skills that are critical to teaching are also relevant in maintaining well-being and in labor market outcomes (Heckman, Stixrud, \& Urzua, 2006; Klusmann et al., 2008; Knudsen et al., 2006).

Domain-general does not imply that skills automatically transfer across domains. In fact, considerable evidence indicates that skills do not easily transfer from one context to another (Baldwin \& Ford, 1988; Melby-Lervåg, Redick, \& Hulme, 2016). This has important implications for educating skills in teachers. Even though skills important to teaching are relevant in other activities, they likely need to be educated in the context of learning to teach and in a form applicable while teaching.

\section{Social, Cognitive and Affective Skills}

Skills are conceptualized in a hierarchal structure, with a higher-order skill construct clustered at the second level by three primary domains of application: social, cognitive and affective. The social, cognitive and affective designations are not rigid or immutable categorizations. Some skills can be applied in multiple ways. Rather, these categories represent functional heuristics that help clarify common aspects of skills while affording specific and differential hypotheses about the relationship of a skill or skill domain to aspects of teaching.

I do not take up the work of proposing a definitive set of instrumental social, cognitive 
and affective skills. Instead, I illustrate the role of skills as an antecedent of learning to teach by highlighting specific skills, through anecdote and empirical data, that appear to be highly relevant. At present, the dearth of research on skills in teaching precludes the construction of a formal taxonomy of instrumental skills. For instance, in some cases measures theoretically important skills do not yet exist. Intuitively, the instrumentality of a skill may differ based on context. For example, one skill may be similarly important from pre-kindergarten to high school whereas another is crucial in one context but secondary in the other. Skill taxonomies will ultimately be important to future theory and research but would be premature now.

\section{An Anecdotal Account of Social, Cognitive and Affective Skills in Teaching}

During my time teaching 8th grade social studies, I had a student named Jeff (name altered). He was inquisitive and thoughtful, especially about history - the subject I taught. He also faced challenges associated with a learning disability and his tendency to act on the edge of accepted norms. He was on the outside, socially speaking, but with close enough proximity to the center to work himself into the mix. Jeff and I forged a solid relationship.

About midway through the year, Jeff started to try on new clothes, new friends and something of a new personality. I recognized all of this as prototypical adolescent behavior. But there was an edge to his experimentation, a latent anger in his interactions with peers that would occasionally bubble up in the classroom. Some of this discontent began spilling over to our interactions and the quality of his work. One weekend, Jeff was involved in a violent exchange with another student that left the school and town communities rattled. As his teacher, I was disappointed. I expressed to him my disappointment and how much more I expected of him. But the manner in which I expressed this disappointment unwittingly communicated other messages. Through subtle behaviors and a times sarcastic intonation, in retrospect I see that I judged him 
and not just his behaviors - I depersonalized him. Latent anger led me to shut him out by nonverbally communicating that he was bad. Predictably for an adolescent receiving this message, he responded with less engagement and more conflict.

As his teacher, I failed Jeff academically, socially and emotionally. My professional obligation was to harness his inherent curiosity and channel it into effort, engagement and the motivation to learn. My actions did the opposite. I did not lack knowledge in my content area, nor did I lack knowledge of effective and age appropriate pedagogy or instructional design. In fact, I was a highly qualified teacher by the standards of the state in which I taught. I failed Jeff because my cognitive biases and emotional reactions went unacknowledged or overwhelmed my capacity to regulate them. I knew how an adult should effectively respond but was unable to act consistent with that knowledge. This failure of enactment contributed to Jeff's worsening academic and social struggles. It also steadily diminished my ability to positively affect him. Less tangibly, I wonder what effect an adult modeling judgment and anger will have on Jeff and other students' responses when their expectations are not met (Bandura \& Walters, 1977).

This anecdote describes an interpersonal relationship with a student that negatively affected his social and academic growth. Overlapping skills apply in instructionally focused interactions. A schema is a generalized heuristic of effective practice synthesized from the accrued teaching experiences (Borko \& Livingston, 1989). Jeff's questions in class during the period in which his behavior worsened continued to reflect topical interest but were often laced with sarcasm. I possessed multiple effective schema of how I could respond. For example, I could have employed a dialogic that segregated the content from his affect. Or I could have modified classroom structures to direct his question into a meaningful peer interaction. Effective schemata were not sufficient for me to enact one, raising the question: What resources did I need 
to afford the flexibility to act in the ways I knew I should? I find surprisingly simple answers.

Greater empathy (resonance with Jeff's emotional state) and perspective-taking (cognitively putting myself in his shoes) would have afforded greater insight into his situation, inspiring kindness towards him (Toi \& Batson, 1982). That kindness in turn would have removed some or most of the defensiveness I was feeling. Anger tends to narrow attentional focus rather than broaden it (Gable, Poole, \& Harmon-Jones, 2015), limiting available schema. Greater patience (skill in bearing anger with fortitude and calm) would have certainly helped, especially when, in the absence of high-levels of empathy or perspective-taking, anger was a natural reaction for me. Greater meta-awareness (awareness of cognitions, sensory phenomena, and emotions; Schooler, 2002) and self- as well as emotion-regulation (skill in context appropriate regulation of behaviors and emotional responses; Klusmann et al., 2008) were needed. Metaawareness can facilitate adaptive self-regulation, to the extent that regulatory skills are available (Dunne, Thompson, \& Schooler, 2019). Lacking capacity in key skills was a root cause of my problem of enactment - my inability to behave in ways I knew to be effective.

\section{Social Forms of Skill}

Social forms of skill refer to skills that are exercised when interacting with others. Many of the skills highlighted in the anecdote above are exemplar social skills, including kindness (i.e., friendliness, generosity), empathy, perspective-taking, and patience. All of these skills can be learned (Luberto et al., 2017; Weng et al., 2013) and are therefore measurable; are differentiable from declarative knowledge (e.g., knowledge about empathy doesn't instantiate empathic behavior) and behavior (e.g., self-report is not always associated with behavior; Hojat, Magione, Nascam, Gonnella, \& Magee, 2005); and are relevant in a wide range of life activities.

\section{Cognitive Skills}


Cognitive skills are intrapersonal skills that relate to cognitions or processes of mind. Self-regulation is perhaps the most widely research cognitive skill in teaching. It is defined as the ability to adaptively regulate one's behaviors in pursuit of goals (Baumeister Vohs, \& Tice, 2007). Although a conglomerate rather than discrete skill, it is associated with teacher wellbeing and instructional quality (Klusmann et al., 2008; Kunter et al., 2013; Robertson-Kraft \& Duckworth, 2014). Perspective-taking, previously associated with social forms of skill, is frequently characterized as "cognitive empathy" because imagining one's self in another's position is a cognitive process (de Vignemont \& Singer, 2006). Perspective-taking illustrates how the deployment of a skill can determine its categorization. When occurring in the presence of a student, perspective-taking might best be characterized as a social form of skill, but when exercised in a moment of reflection, it may be more accurately described as a cognitive skill.

Meta-awareness may mediate learning to effectively teach. As a background monitoring of unfolding experience that provides insight into one's current state, meta-awareness instantiates a space for reflection and responsivity, two key features of effective teachers (Ball \& Cohen, 1999; Janssen et al., 2015). For example, it can bring into awareness the recognition that the pedagogy one is enacting is inspiring learning or that one's emotional state is dictating responses to students. Its presence affords a workspace for deliberating which schema, if multiple are available, is the most appropriate response (Dahl, Lutz, \& Davidson, 2015) whereas its absence indicates that reflexivity and unconscious habit are dictating behavior.

Teachers, especially less experienced teachers, report classroom management as one of the most challenging and stressful aspects of teaching (Greenberg, Putnam, \& Walsh, 2014). All teachers at some point experience a student or group of students that struggle to maintain focus on learning goals. Frustration is a natural response to repeatedly having to redirect behavior. But 
reacting out of frustration degrades the classroom climate and further disrupts learning (Jennings \& Greenberg, 2009). Meta-awareness can intervene in this cascade. Becoming aware of the cognitions, sensations and emotions associated with rising frustration materializes the opportunity to self-regulate, change instructional approach, or adjust behavior in some other way. When such opportunities are engaged with adequate capacity in self-regulation, kindness, patience or another relevant skill, the possibility for effective responding to even the most challenging teaching moments becomes possible.

\section{Affective Skills}

Affective skills are skills directed toward the identification or regulation of emotional experience. Empathy, previously listed as a social form of skill can also be thought of as an affective skill. Emotion recognition, the ability to recognize, identify and distinguish emotional states, is an important emotional intelligence skill (Mayer, Caruso, \& Salovey, 2016). Emotion regulation is distinguished here from self-regulation. The latter focuses on regulation of cognitive processes such as attention and the former on affective experience. Because developing warm and caring relationships is crucial to establishing a functional classroom environment, emotion regulation is likely a key modulator of effective classroom management and a core constituent of teacher resilience (Jennings \& Greenberg, 2009; Mansfield et al., 2012).

\section{Integrative Teacher Education}

Integrative teacher education is the marriage of explicit, systematic education of social, cognitive and affective skills with historically dominant teacher education methods that emphasize teaching-relevant knowledge (Grossman \& McDonald, 2008). Although improving knowledge education is always possible, I assume that high-quality teacher education is already proficient in knowledge development. Thus, I understand current teacher education to be 
incomplete rather than inherently flawed (e.g., Greenberg, McKee, \& Walsh, 2013). There is currently too little emphasis on and no systematic approach to developing social, cognitive and affective skills (Sutton et al., 2009).

\section{Knowledge is Necessary but Not Sufficient}

Although necessary, knowledge is not sufficient for enactment (Ball \& Cohen, 1999). In most countries and American states, licensing criteria largely or exclusively evaluate teachingrelevant knowledge competencies (OECD, 2019; US DOE, 2014). Yet licensure scores (Goldhaber, 2007), quality of undergraduate institution, possession of an advanced degree, and even years of teaching experience, all indicators of greater knowledge, show little to no systematic relationship to teacher performance (Rivkin, Hanushek, \& Kain, 2005). These data have led some researchers to deduce that skills explain significant variance in teacher effectiveness (Jackson, 2012; Rockoff, 2004). As Shulman (1986) put it, "mere content knowledge is likely to be as useless pedagogically as content-free skill” (p. 8).

Promisingly, policy makers are increasingly attending to the importance of skill development. However, attention has overwhelmingly centered on student skill development (but see Jennings \& Greenberg, 2009; Roeser, Skinner, Beers, \& Jennings, 2012). At the same time that SEL programs for students expand, it remains unusual for teachers delivering SEL curricula to receive training in social-emotional competency development (Schonert-Reichl, Kitil, \& Hanson-Peterson, 2017). This incongruency appears to reflect the assumption that teachers already possess sufficient levels of social, cognitive and affective skills. But where did they learn these skills if programs for students are only recently becoming more widespread and such programs for teachers are rare? Integrative teacher education assumes that just like teachingrelevant knowledge, teaching-relevant skills must be systematically educated. 


\section{Educating Skills}

Because comparatively little attention has been placed on teacher skill development, research on skills education is sparse. Extant research can be divided into two types. The first comprises methods that are designed explicitly around skills cultivation. Schonert-Reichl (2019) recently suggested teacher SEL programs as a pathway to skill development. Emotional Intelligence (EI) interventions may effectively educate the narrower set of skills encompassed by EI (Hen \& Sharabi-Nov, 2014). I highlight mindfulness-based interventions (MBIs) as a promising paradigm for skills education (Roeser et al., 2012; Shankland \& Rosset, 2017). Although nascent, MBI research with teachers is more developed than SEL or EI research. In addition, the practice of mindfulness is a self-contained cycle of learning, practice and reflection that mirrors the decomposition, recomposition and rehearsal framework of practice-based teacher education, except it is oriented toward skill strengthening rather than enactment of a core teaching practice. The second type of skills research in teachers consists of methods that do not explicitly emphasize skills education but nevertheless appear to result in skill strengthening.

\section{The Science of Potential}

Before reviewing evidence for skills education, it is important to contextual the concept within historical scientific views on the topic. Until recently, scientific orthodoxy held that the human brain reached maturity around the age of 18 and from that time on was fixed. Similarly, personality has long been treated as stable trait. We now know that these conclusions are erroneous. The brain remains plastic throughout the lifespan, producing new neurons in regions critically involved in learning and memory (Eriksson et al., 1998). Personality can be altered through intervention (Roberts, Luo, Briley, Chow, Su, \& Hill., 2017). In addition to functional and structural changes associated with lifespan developmental processes, neuroplastic alterations 
can be traced backed to specific behaviors and experiences and intentionality can play a determining role in the change instantiated (Goleman \& Davidson, 2017).

\section{Explicit Skills Education Interventions: Mindfulness}

Mindfulness is commonly defined as the practice of paying attention, on purpose, to present-moment experience with an attitude of non-judgment or acceptance (Kabat-Zinn, 2013). In the scientific literature, it has been operationalized as a trait and as a skill. Most mindfulnessbased interventions (MBIs) involve instruction in a series of formal and informal techniques that share the primary aim of developing mindfulness skills. The Five Facet Mindfulness Questionnaire (Baer et al., 2008), a widely used self-report of mindfulness, captures five mindfulness skills: the ability to observe experience (e.g., thoughts, sensory phenomena, emotions), the ability to describe experience, the ability to act with mindful awareness, the ability to be aware of but not reactive to inner experience, and the ability to be aware of but not judge inner experience. Meta-awareness, attention regulation, emotion regulation and patience are essential aspects of mindfulness skills.

Increasingly, MBIs are incorporating non-mindfulness styles of meditation (Authors blinded, 2018). In particular, practices that involve the intentional cultivation of feelings of goodwill and warm wishes toward others (i.e., loving-kindness practices) and a desire to reduce hardship and suffering (i.e., compassion practices) are now ubiquitous in MBIs (Stahl \& Goldstein, 2010). Authors blinded (2020) describe these styles of practice as connection practices. Connection practices target mostly social forms of skills proposed to be antecedent to effective teaching (e.g., empathy, perspective-taking and kindness).

\section{Theoretical Framework of Mindfulness}

Theorists of mindfulness' salutary effects argue that reduced stress, increased well-being, 
resilience, sense of agency, clarity of purpose, and prosocial disposition and behavior are the result of enhanced social, cognitive and affective skills developed through repeated practice (Dahl et al., 2015; Shapiro, Carlson, \& Astin, \& Freedman, 2006; Vago \& Silbersweig, 2012). Data support these theories. In general population and clinical samples, MBIs reduce stress and stress related negative affect (e.g., anxiety and depression), increase mindfulness and other skills, and improve prosocial dispositions and behaviors (Goldberg et al., 2017; Luberto et al., 2017). Of importance, greater practice amount and higher practice quality are associated with enhanced positive outcomes (Goldberg, Del Re, Hoyt, \& Davis, 2014; Authors blinded, 2020).

The practice of mindfulness is a self-contained cycle of learning, practice and reflection. Initially, learning includes declarative learning about and procedural learning in the techniques used to develop mindfulness skills. For example, establishing a posture conducive to mindfulness practice; harnessing attention to systematically observe sensations in different parts of the body; and how to use intention to shape the quality of attentiveness placed on whatever comes into awareness. As someone repeatedly practices posture, attention, and the quality of attention, myriad thoughts, emotions and sensations arise. Each arising furthers the opportunity to maintain awareness, or when distraction occurs, activate meta-awareness to first notice distraction and then regulate attention back to the object of the mindfulness practice. To the extent that this process elicits reactive emotion - "I got distracted again! I'm supposed to be paying attention!" the opportunity to cultivate patience, or a non-reactive stance to distraction and the reaction to distraction trains the mind to rest unperturbed. Through practice, skills such as focused attention, flexibility of attention, meta-awareness, and patience are strengthened.

Connection practices similarly function as cycles of learning, practice and reflection. Whereas mindfulness techniques emphasize the practice of cognitive skills, connection practices 
focus on strengthening social forms of skill. For example, loving-kindness practice, or the generation of feelings of warmth and good wishes to specific and non-specific others, often begins with a reflection on how others, even those we struggle with, share the basic wish to be happy, healthy and safe. More elaborated versions involve the deliberate practice of perspectivetaking and empathy. How might my responses to Jeff might have unfolded if, early in the process of escalating conflict, I had spent time deliberately developing perspective, empathy, patience and kindness toward him and his experiences?

In function, formal practice in MBIs decompose complex daily life applications of skills into more discrete and comprehensible chunks by providing a relatively controlled workspace for the rehearsal of social, cognitive and affective skills (Dahl et al., 2015). To this end, formal practice opportunities usually involve restricting sensory input (e.g., sound, visual input, movement). It is extremely difficult amidst the cacophony of streams of thought, sensory input, movement, interactions, and reactions to all of the above to maintain clear and focused attention on, for example, a sensation in the body. It is similarly difficult amidst the complexity of a classroom to adaptively respond to the moment. Proponents of practice-based teacher education argue that structured opportunities to practice discrete elements of effective teaching behaviors provide the basis for later recomposing that component during the full complexity of teaching. The container of formal mindfulness or connection practice foregrounds processes of mind, affording increased opportunities to strengthen social, cognitive and affective skills that can then be integrated into the complexity of daily life activities, including teaching.

Skills and development of the core practices of teaching are positioned at different stages of the IM's process of learning to teach. As noted in the section of the difference between skills and behavior, skills exist independent of the demonstration of core teaching practices but are 
necessary antecedents to them. In other words, skill capacity (along with knowledge) explains the extent to which decomposition, recomposition, and rehearsal of core practices are effective as a basis for learning. Thus, the foundation for effective integrative teacher education is the education of knowledge and skills in preparation for (or perhaps concurrent to) the cycles of learning, practice and reflection suggested by practice-based theorists. I assume that integrating skills education into teacher education is important to skill application when teaching.

\section{Research on Mindfulness-Based Interventions with Teachers}

Results from MBI studies with teachers are promising. In a randomized controlled trial (RCT) MBI with 113 elementary and secondary school teachers, Roeser et al. (2013) observed significant MBI group reductions in anxiety and depression as well as significant increases in attention, awareness and meta-awareness skills. Most important, MBI group follow-up reductions in stress and burnout were fully mediated by post-intervention mindfulness skill gains, providing causal evidence that increased skill benefits teacher mental health. In a RCT of 82 female teachers, Kemeny et al. (2012) reported significant MBI group reductions in anxiety and rumination as well as significant increases in present-moment attention (i.e., a mindfulness skill), positive emotion, and the ability to perceive subtle emotions in faces (i.e., empathy).

Placed in the context of the more mature MBI literature in other populations, these data accord with the conclusion that MBIs effectively promote skills that improve well-being and psychological functioning. Whether MBIs are relevant to supporting teacher education depends on these factors and the degree to which skills education leads to increased enactment of the core practices of teaching. This question has only begun to be addressed in research, but extant data are suggestive. In the largest MBI RCT with teachers to date $(N=224)$, Jennings et al. (2017) found significant improvements post-intervention in adaptive emotion regulation and 
mindfulness skills. Critically, MBI teachers also demonstrated improvements on the Emotional support domain of the Classroom Assessment Scoring System (CLASS; La Paro et al., 2004) compared to controls; evidence that the skills learned during the MBI transferred to greater enactment of effective behaviors in the classroom.

In a RCT study design that closely approximates the proposal of integrative teacher education, Authors blinded (2020) integrated mindfulness and connection practices into an undergraduate elementary education preservice teacher education program. In addition to reporting significant post-test gains on mindfulness skills associated with awareness and metaawareness, at the 6-month follow-up the MBI group showed significant gains on all three the CLASS's main domains of effective teaching. Notably, the follow-up CLASS observation occurred when soon-to-graduate preservice teachers were in student teaching and had taken over all classroom responsibilities, allowing the closest possible approximation of professional teaching. Consistent with practice-based theorizing, greater CLASS gains were moderately correlated with higher average daily mindfulness practice, suggesting that with more skills practice comes greater enactment of effective teaching behaviors.

\section{Implied Models of Skill Development}

The last decades have witnessed a number of exciting innovations in teacher education, especially concerning the utilization of technology. Coaching or mentoring, while not a new concept, has been modernized by employing technologies varying from videos of teaching to simulated teaching environments. Mounting evidence suggests that high-quality coaching effectively improves teaching behaviors (Kraft, Blazar, \& Hogan, 2016). Although not focused on social, cognitive and affective skills development, coaching interventions likely develop these skills. The My Teaching Partner (MTP; Allen, Pianta, Gregory, Mikami, \& Lun, 2011) coaching 
intervention, designed around the CLASS framework, aims to develop teacher understanding of the CLASS framework so that they gain skill in identifying effective teaching behaviors.

In a RCT of 440 early education teachers, Hamre and colleagues (2012) found that MTP teachers performed significantly better than controls on many of the major domains and subdimensions of the CLASS, including emotional support, regard for student perspectives, instructional learning formats, and quality of feedback, and significantly outperformed the control group in their ability to identify effective teaching practices when watching videos of others teaching. Crucially, enhanced skill in identifying effective teaching behaviors partially mediated improvements in instructionally supportive interactions among intervention teachers.

In another RCT involving a year-long version of MTP this time with secondary teachers (Allen et al., 2011), MTP teachers improved on the CLASS in the year following the intervention and their students that year demonstrated corresponding achievement gains. In this study, MTP teachers not only learned to identify effective behaviors, they regularly recorded themselves teaching, sent the videos to expert CLASS coders who selected segments that revealed areas for improvement, and then conferenced with the experts about these segments.

Simulated or virtual environments have also been harnessed as coaching opportunities. Cohen, Wong, Krishnamachari, and Berlin (2020) randomly assigned preservice teachers to one of three brief interventions (5 minutes): coaching, real-time coaching through an earpiece, or reflection only. They observed that teachers assigned to both of the coaching conditions significantly improved in their redirection of off-task student behavior and in their overall quality compared to the reflection only group. Notably, both coaching groups also had significantly less harsh perceptions of students' off-task behavior and were more likely to endorse non-punitive responses, intimating increased activation of skills such as patience. In an early study on 
simulated learning environments with preservice teachers, Yeh (2004) reported that teachers assigned to a coaching group significantly improved their critical-thinking instruction relative to controls through feedback generated increases in self-awareness.

Although strengthening social, cognitive and affective skills are not articulated as central targets of these interventions, skills development is nevertheless an implied mechanism of change. High-quality coaching represents an exogenous compass that directs attention and awareness onto the strengths and weaknesses of one's behaviors. In addition to attention and meta-awareness, when focal moments of coaching implicate empathy, patience, self-regulation or emotion-regulation, or implicate callousness, anger, or punitive responding, skills are implicitly identified as prime targets for learning, practice and reflection. An important question for future research is whether explicit identification of and strategies for educating skills improves the efficacy of these interventions.

\section{On-going Cycles of Learning, Practice and Reflection and Developed Automaticity of Core Practices.}

Consistent with practice-based theories of teacher education (e.g., Ball \& Cohen, 1999; McDonald et al., 2013), integrative teacher education proposes that skills and knowledge education must be implemented in conjunction with opportunities for practice and reflection. Learning is the process of acquiring teaching-relevant knowledge and skills and along with opportunities for practice and reflection, is the focus of integrative teacher education. Practice is the opportunity to apply what has been learned. Reflection can be anticipatory, contemporaneous or retrospective (Loughran, 1995). Anticipatory reflection can prepare a teacher for the resources that might be called upon, priming the system to adaptively respond. It is dependent on wellhoned teaching schema. Retrospective reflection can bring clarity about how and when to 
appropriately enact core practices. In turn, clarity about the efficacy of certain practices and their implementation is critical to developing well-honed schemas. Contemporaneous reflection is the least emphasized and the most difficult because it involves in-the-moment reflection and adaptation (Authors blinded, 2017).

Cycles of learning, practice and reflection are already embedded in teacher education. Scholars have argued that greater proximity between the academy and the places where practice actually occurs (i.e., schools) and between teaching foundations (e.g., content knowledge) and teaching methods (e.g., strategies of teaching) are solutions to the problem of enactment (Grossman, Hammerness, \& McDonald, 2009; Zeichner, 2010). However, the provision of these cycles does not uniformly promote more effective teaching (Cohen et al., 2020; Emmer \& Stough, 2001; Ronfeldt, 2015). This is because levels of knowledge and skill determine the quality and therefore the outcomes of practice and reflection. Absent skills education, the skills brought into teacher education vary widely (Cohen et al., 2020) and as consequence, so does a teacher's ability to harness practice and reflection into learning.

\section{Core Practices}

Teaching occurs in a series of contextualized moments defined by the people, place, thoughts, sensations and emotions occurring at that time (Ball \& Cohen, 1999). This particularity makes it impossible to prescribe effective responsivity (Janssen et al., 2015; Pianta \& Hamre, 2009), but practice-based theorists argue that operationalizing the core practices of teaching is not only possible but necessary (Grossman et al., 2009). In an early iteration of core practice theorizing, Scriven (1994) organized the duties of teaching into categories (e.g., professionalism, assessment competence, content knowledge) under the premise that these duties represented readily observable behaviors that formed the backbone of successful teaching. 
Contemporary core practice taxonomies include Grossman et al.’s (2009) high leverage practices. High leverage practices are those that occur with high frequency in teaching; those that novices can enact in classrooms across different curricula or instructional approaches; those that novices can actually begin to master; those that allow novices to learn more about students and about teaching; those that preserve the integrity and complexity of teaching; and those that are research-based and have the potential to improve student achievement. Greenberg, Putnam and Walsh (2014), following a comprehensive literature review of effective teaching, proposed five core practices. The "big five" consist of establishing rules to communicate expectations, building structures that guide students across learning contexts, reinforcing positive behavior with praise, consistently enforcing rules through consequences to limit misbehavior, and engaging students through lessons that include opportunities for student participation.

Work on core practices describes the general qualities of foundational teaching practices (Grossman et al., 2009) and the broad domains in which these practices reside (Greenberg et al., 2014). Proposals of discrete core practices, some domain-specific, have also been advanced. For example, Lampert and colleagues (2010) positioned dialogic forms that support specific learning processes such as eliciting and engaging with students' mathematical thinking as core practices in mathematics instruction. Windschilt, Thompson, Braaten, \& Stroupe (2012) also highlighted specific science discourse strategies and planning around the higher-order concept (i.e., the big idea) as core practices. In literacy instruction, metacognitive reading strategies is an exemplar core practice (Ahmadi, Ismail, \& Abdullah, 2013).

Identifying core practices remains a robust and important area of research. In order to capitalize on innovative opportunities for practice and reflection, teachers need sufficient knowledge and skill to make these opportunities meaningful. When rich opportunities for 
practice and reflection are engaged with sufficient knowledge and skill, teachers incrementally build: a) effective practice schemas (e.g., of core practices); b) competency in enacting those schemas (emerging automaticity); and c) confidence in their capacity to adapt to the particularities of the moment (i.e., self-efficacy). The reciprocating arrows in the IM illustrate this cycle as a feed-forward loop to greater automaticity of core practices and a feedback loop into enhanced skill and knowledge learning.

\section{Automaticity}

Automaticity refers to learning stage at which foundational practices have become automatic or routine (Janssen et al., 2015). Automaticity is conditional on what Borko, Liston and Whitcombe (2007) framed as dispositions. The authors' define a disposition as the tendency to act in a certain way which, importantly, is contingent on knowledge and skills (Borko et al., 2007). For instance, when knowledge of effective classroom management is coupled with a skill such as kindness, the disposition of classroom management responses will reflect both this knowledge and skill. A disposition is probabilistic not deterministic. As a disposition becomes reinforced through practice, continually adapting the basic disposition to the specific needs of the moment, the probability of skill and knowledge manifesting in enactment of an effective behavior (i.e., instantiation of a core practice) increases until the point at which enactment becomes an automatic response, with important consequences (Fiorella, 2020).

Automaticity of the core practices of teaching represents the juncture at which the problem of enactment has been surmounted. However, it is not the end of learning. Teaching remains an extraordinarily complex, emotional and demanding occupation with many nonroutine components (Hargreaves, 1998; Janssen et al., 2015; Shulman, 2004). The demands of this complexity affect memory and attention, cognitive load, momentary task-relevant processes, 
and motivation (Feldon, 2007; Plass \& Kalyuga, 2019). Stress and heightened emotionality further diminish cognitive and affective resources. Automaticity, the efficient and effortless demonstration of core practices (Feltovich, Prietula, \& Ericsson, 2006), releases limited cognitive and affective resources so that they are available to attend to the non-routine aspects of effective practice (Darling-Hammond \& Bransford, 2005; Janssen et al., 2015).

Expert teachers are more efficient at planning than novices and produce more effective lessons (Berliner, 1986; Borko \& Livingston, 1989; Tsui, 2005). They also demonstrate increased awareness of classroom dynamics (Schempp, Tam, Manross, \& Fincher, 1998) and have access to larger and more integrated schema of effective practice that allow them to recognize patterns in what can seem to be incoherent or chaotic movements of a classroom (Berliner, 1986; Sabers, Cushing, \& Berliner, 1991). The applicability and functionality of experts' schema is evidenced in their increased capacity to tailor instruction to the differing needs of students (Schempp et al., 1998) and adapt to unpredictable classroom events (Borko \& Putnam, 1996). Along with larger, more integrated and functional schema and the ability to discern relevant from irrelevant contextual information, automaticity is a building block for expert practice (Chi, Glaser, \& Farr, 2014; Darling-Hammond \& Bransford, 2005; Feltovich et al., 2006). Knowledge and skill are the antecedents that imbue practice and reflection with meaning, leading to automaticity and in turn providing the opportunity for adaptive expertise.

\section{Enactment of Effective Teaching Behaviors}

In the IM, reliable enactment of effective teaching behaviors occurs after automaticity of core practices is achieved. Enactment is putting into practice, materializing or embodying a behavior the promotes student learning. Student learning is defined broadly to include academic, cognitive, social, and emotional domains. Enactment encompasses all effective teaching 
behaviors, of course including core practices. Whereas scholars have operationalized core practices as foundational (e.g., Grossman et al., 2009), enactment is the fully elaborated expression of all of the academic, social, cognitive, and emotional domains that teacher behaviors operate within and affect in students. A teacher that is able to reliably enact effective teaching behaviors across these domains is an expert teacher.

Because effective teaching is particular to the moment, complex and cannot be prescribed, operationalizing enactment has long been a contentious topic in educational research (Amrein-Beardsley \& Geiger, 2017; Darling-Hammond \& Youngs, 2002; Rabinowitz \& Travers, 1953). For the purpose of illustrating the culmination of the developmental process outlined in the IM, I have elected to use the Classroom Assessment Scoring System (CLASS; La Paro et al., 2004) as the heuristic for enactment of effective teaching. The CLASS is not without limitations (e.g., Berliner, 2018; Campbell \& Ronfeldt, 2018). Defensible alternative operationalizations of enactment exist. For example, for researchers interested in language arts instruction, the PLATO (Grossman et al., 2009) could be inserted in place of CLASS or for those interested in mathematics instruction, the MQI (Hill et al., 2008). The modularity of the IM allows for this flexibility. I have selected the CLASS because it encompasses academic, cognitive, social and emotional domains of teaching, is structural consistent across content areas and levels, and has a well-articulated theoretical framework (CLASS; Pianta \& Hamre, 2009). These features allow me to present the IM as a general model of teacher education and learning to teach.

\section{Classroom Assessment Scoring System as Effective Teaching Behaviors}

The CLASS operationalizes enactment in a hierarchal fashion, with a tripartite higher order structure consisting of three main domains: Instructional support, Classroom organization, and Emotional support (but see Hamre, Hatfield, Pianta, \& Jamil, 2014). In upper elementary (3rd 
- 6th grade) and secondary (7th grade and above) CLASS tools, a single item higher-order fourth domain, Student engagement, is added. Nested within each of the three major latent domains are multiple indicator behaviors (Pianta \& Hamre, 2009). Indicator behaviors are not specific routines, but instead indicators of the quality of teacher-student interaction.

In brief, Instructional supports reflect teacher behaviors intended to support student meaning-making and cognitive activation. The dimensions of Instructional supports: concept development, quality of feedback, and language modeling are observed through indicator behaviors like analysis and reasoning, creativity, encouragement of responses, conversation, and open-endedness. In upper elementary and secondary level observations, Instructional supports are modified and expanded to include instructional learning formats (e.g., variety of modalities and materials), content understanding (e.g., depth of understanding, background knowledge), analysis and inquiry (e.g., metacognition), instructional dialogue (similar to Language modeling) and quality of feedback.

The Classroom organization domain refers to teacher behaviors focused on structuring and organizing the classroom learning context, both in physical manifestation (e.g., chairs and desks) as well as the interpersonal relationships that occur within it. Behavior management, productivity, and negative climate comprise the dimensions of Classroom organization. Behavior management can be observed through indicator behaviors including clear expectations, proactiveness, effective redirection of behavior and the types of student behaviors observed in the classroom. Productivity can be ascertained by observing routines, transitions, preparation and the maximizing of learning time. Negative climate is assessed by indicator behaviors such as punitive control, disrespect and negative student affect.

Emotional supports, the third and final higher-order domain, represents the overall 
emotional climate and quality of interpersonal dynamics within the classroom. The dimensions within Emotional supports: positive climate, teacher sensitivity, and regard for student perspectives are observed through indictor behaviors such as positive affect, relationships and communications (positive climate), teacher awareness and responsivity to student social, emotional and academic needs, as well as the level of student comfort (teacher sensitivity), flexibility and student focus, connections to students lives, and meaningful peer to peer interactions (regard for student perspectives).

The three (or four) factor model advanced by the CLASS provides a coherent, categorization of effective teaching behaviors that affords specific hypotheses about the relationships of knowledge and skills to each category. These are shown in the IM by the tone or style of arrow pointing from knowledge or skills to a domain of enactment. For example, based on data showing that pre-K teachers score lowest on instructional support (e.g., Office of Head Start, 2018) and the contention that skills are not currently educated, the IM predicts that skills are relatively more important to enactment of instructional support than knowledge. In contrast, the model shows knowledge to be relatively more central to classroom organization, due to the contribution of schema to enactment of effective classroom organization behaviors.

Although the IM does not depict relationships at this level of fidelity, researchers may wish to differentiate the roles of knowledge and skill to effective teaching with more granularity. For instance, while knowledge is predicted to be relatively more influential than skill in classroom organization, certain indicator behaviors within this domain may be more strongly associated to skill (e.g., effective redirection of behavior). Alternatively, hypotheses about the differential roles of specific skills to CLASS domains or indicator behaviors are both possible and likely to produce knowledge that informs teacher education in the future. 


\section{Proposed Outcomes of Integrative Teacher Education}

The most important proximal outcome of integrative teacher education is a structure for educating teachers who reliably enact effective teaching behaviors. The skills in the IM that mediate this outcome are associated with improved teacher well-being and reduced stress (Klusmann et al., 2008). Therefore, the IM predicts increased teacher well-being and reduced stress will follow integrative teacher education (Jennings \& Greenberg, 2009; Roeser et al., 2012). Teacher stress is an ubiquitous factor in early career attrition, a phenomenon that continually depletes the limited resources available in educational systems (Carroll, 2007; PDK International, 2019). Even small reductions in turnover rates through increased skill will reduce costs and improve staff continuity within schools.

Students benefit when teachers reliably enact effective teaching behaviors (Allen et al., 2011). Because effective teaching behaviors are equitable, reductions in race and socioeconomic achievement gaps are expected to attend increased enactment of core practices (Gregory et al., 2016). Less directly but no less important, as teacher skill levels increase and their behaviors reflect this learning, students will likely develop these same skills (Bandura \& Walters, 1977). To the extent that teacher skills education is paired with equivalent curricula for students (e.g., SEL, mindfulness), student skill learning will be enhanced (Jennings \& Greenberg, 2009).

The benefits of integrative teacher education, while varied, are not a panacea for the ailments of societal and educational inequities; comprehensively addressing inequities in educational outcomes, teacher stress, teacher effectiveness and other challenges facing educational systems and the societies that construct them will require more than educating knowledge and skills in teachers. At the same time that researchers and policy makers strive to improve teacher education and thereby the quality of teaching, we must ask why, across the 
globe, teachers experience elevated stress relative to other professions (McCarthy, 2019) and whether what society asks of teachers is reasonable. Integrative teacher education is a solution to the problem of enactment, but improving teaching is only part of the solution to improving educational systems.

\section{Future Directions}

The hypotheses stipulated in the IM require rigorous empirical examination. In some cases, measures do not yet exist for potentially important skills or knowledge domains. Further theoretical work explicating skills and basic science developing and validating novel assessments are needed (Duckworth \& Yeager, 2015). Applied research that combines assessment of teacher behaviors (e.g., teaching observations) with assessment of knowledge and skill will shed important light on key elements of the IM. Within basic and applied research, myriad questions remain. What is the relative importance of social, cognitive and affective skill? Does their importance differ based on the domain of enactment? Are different skills required at different stages of learning to teach? Does strength in one skill or one domain compensate for relative weakness in another? In addition, future research should investigate the impact of context on both the learning and the application of skills and knowledge in the classroom.

\section{Educational Psychology and Teacher Education}

Attempts to improve teaching and teacher education may be among the most feasible and impactful targets for educational reform. Educational psychology methods are ideally suited to the task of identifying and operationalizing the individual differences that support effective teaching (Hodis \& Hancock, 2016). Yet the impact of educational psychology on teacher education is limited (Hoy, 2000; Patrick, Anderman, Bruening, \& Duffin, 2011).

Examples of educational psychology research catalyzing paradigmatic shifts in teacher 
are instructive. Standardized, observational tools developed by educational psychologists (e.g., CLASS, Pianta \& Hamre, 2009; MQI, Hill et al., 2008) have become widely adopted in teacher education. This is at least partly due to the fact that these measures thoroughly integrate theory and research drawn from both traditions. In order for educational psychologists to maximally impact teacher education, those working at the intersection of the fields must be attentive to teacher education scholarship and integrate it within their own research. I attempted this approach by synthesizing evidence from both literatures. Greater collaboration and crossfertilization will benefit both disciplines, but most importantly improve teacher quality.

\section{Conclusions}

Teaching is complex and demanding. Learning to teach depends on knowledge and skills, but skills are not systematically educated as part of teacher education. Integrative teacher education establishes a framework in which teaching-relevant knowledge and skills are central elements of teacher education. Mindfulness and connection practice interventions are suggested as a paradigmatic form of skill development. The Integrative model for teacher education places the proposal of integrative teacher education within a developmental model of learning to teach that illustrates the importance of knowledge and skills education to developing automaticity of core practices, in part by optimizing the provision of cycles of learning, practice and reflection already built in to teacher education, in turn producing increasingly reliable enactment of effective teaching behaviors. Although not a panacea, the IM is both a framework for understanding the process of learning to teach and a model of teacher education that educates all of the antecedents of effective teachers.

\section{References}

Ahmadi, M. R., Ismail, H. N., \& Abdullah, M. K. K. (2013). The Importance of metacognitive 
reading strategy awareness in reading comprehension. English Language Teaching, 6(10), 235-244.

Allen, J. P., Pianta, R. C., Gregory, A., Mikami, A. Y., \& Lun, J. (2011). An interaction-based approach to enhancing secondary school instruction and student achievement. Science, 333(6045), 1034-1037.

Almlund, M., Duckworth, A. L., Heckman, J., \& Kautz, T. (2011). Personality psychology and economics. In E. A. Hanushek, S. Machin, \& L. Woessmann (Eds.), Handbook of the Economics of Education (Vol. 4, pp. 1-181). doi:10.1016/B978-0-444-53444-6.00001-8

Amrein-Beardsley, A., \& Geiger, T. (2017). All sizzle and no steak: Value-added model doesn't add value in Houston. Phi Delta Kappan, 99(2), 53-59. doi:10.1177/0031721717734191

Authors blinded (2017).

Authors blinded (2018).

Authors blinded (2020).

Baer, R. A., Smith, G. T., Lykins, E., Button, D., Krietemeyer, J., Sauer, S., Walsh, E., Duggan, D., \& Williams, J. M. G. (2008). Construct validity of the five facet mindfulness questionnaire in meditating and nonmeditating samples. Assessment, 15(3), 329-342. doi:10.1177/1073191107313003

Baldwin, T. T., \& Ford, J. K. (1988). Transfer of training: A review and directions for future research. Personnel Psychology, 41(1), 63-105. doi:10.1111/j.1744-6570.1988.tb00632.x

Ball, D.L., \& Cohen, D. K. (1999). Developing practice, developing practitioners: Toward a practice-based theory of professional education. Teaching as the Learning Profession: Handbook of Policy and Practice, 1, 3-22.

Ball, D.L., Payne, W. H., \& Hill, H. C. (2009). Measuring teacher quality in practice. In 
Measurement Issues and Assessment for Teaching Quality (pp. 80-98).

Bandura, A., \& Walters, R. H. (1977). Social learning theory (Vol. 1). Englewood Cliffs, NJ: Prentice-hall.

Barr, A. S. (1929). Characteristic differences in the teaching performance of good and poor teachers of the social studies. Public school publishing company.

Baumeister, R. F., Vohs, K. D., \& Tice, D. M. (2007). The strength model of self-control. Current Directions in Psychological Science, 16(6), 351-355. doi:10.1111/j.14678721.2007.00534.x

Baumert, J., \& Kunter, M. (2013). The COACTIV model of teachers' professional competence. In Cognitive activation in the mathematics classroom and professional competence of teachers (pp. 25-48). Springer.

Berliner, D. C. (1986). In pursuit of the expert pedagogue. Educational researcher, 15(7), 5-13.

Berliner, D. C. (2018). Between Scylla and Charybdis: Reflections on and problems associated with the evaluation of teachers in an era of metrification. Education Policy Analysis Archives, 26(0), 54. doi:10.14507/epaa.26.3820

Borko, H., Liston, D., \& Whitcomb, J. A. (2007). Apples and fishes: The debate over dispositions in teacher education. Journal of Teacher Education, 58(5), 359-364. doi:10.1177/0022487107309977

Borko, H., \& Livingston, C. (1989). Cognition and improvisation: Differences in mathematics instruction by expert and novice teachers. American Educational Research Journal, 26(4), 473-498. doi:10.2307/1162861

Borko, H., \& Putnam, R. T. (1996). Learning to teach. In D. C. Berliner \& R. C. Calfee (Eds.), Handbook of educational psychology (p. 673-708). Prentice Hall International. 
Campbell, S. L., \& Ronfeldt, M. (2018). Observational evaluation of teachers: Measuring more than we bargained for? American Educational Research Journal, 55(6), 1233-1267. doi:10.3102/0002831218776216

Carroll, T. (2007). Policy brief: The high cost of teacher turnover. National Commission on Teaching and America's Future.

Cheng, A., \& Zamarro, G. (2018). Measuring teacher non-cognitive skills and its impact on students: Insight from the Measures of Effective Teaching Longitudinal Database. Economics of Education Review, 64, 251-260. doi:10.1016/j.econedurev.2018.03.001

Chi, M. T., Glaser, R., \& Farr, M. J. (2014). The nature of expertise. Psychology Press.

Cochran-Smith, M., \& Power, C. (2010). New directions for teacher preparation. Educational Leadership, 67(8), 6-13.

Cohen, J., Wong, V., Krishnamachari, A., \& Berlin, R. (2020). Teacher coaching in a simulated environment. Educational Evaluation and Policy Analysis. doi:10.3102/0162373720906217

Dahl, C. J., Lutz, A., \& Davidson, R. J. (2015). Reconstructing and deconstructing the self: Cognitive mechanisms in meditation practice. Trends in Cognitive Sciences. doi:10.1016/j.tics.2015.07.001

Darling-Hammond, Linda, \& Bransford, J. D. (2005). Preparing Teachers for a Changing World: What Teachers Should Learn and Be Able to Do. John Wiley and sons.

Darling-Hammond, L., \& Youngs, P. (2002). Defining "highly qualified teachers": What does “scientifically-based research" actually tell us? Educational Researcher, 31(9), 13-25. doi:10.3102/0013189X031009013

de Vignemont, F., \& Singer, T. (2006). The empathic brain: How, when and why? Trends in 
Cognitive Sciences, 10(10), 435-441. doi:10.1016/j.tics.2006.08.008

Duckworth, A. L., \& Yeager, D. S. (2015). Measurement matters: Assessing personal qualities other than cognitive ability for educational purposes. Educational Researcher, 44(4), 237-251. doi:10.3102/0013189X15584327

Dunne, J. D., Thompson, E., \& Schooler, J. (2019). Mindful meta-awareness: Sustained and nonpropositional. Current Opinion in Psychology. doi:10.1016/j.copsyc.2019.07.003

Eichenbaum, H. (2000). A cortical-hippocampal system for declarative memory. Nature Reviews Neuroscience, 1(1), 41. doi:10.1038/35036213

Emmer, E. T., \& Stough, L. M. (2001). Classroom management: A critical part of educational psychology, with implications for teacher education. Educational Psychologist, 36(2), 103-112. doi:10.1207/s15326985ep3602_5

Ericsson, K. A. (2017). Expertise and individual differences: The search for the structure and acquisition of experts' superior performance. Wiley Interdisciplinary Reviews: Cognitive Science, 8(1-2). doi:10.1002/wcs.1382

Eriksson, P. S., Perfilieva, E., Björk-Eriksson, T., Alborn, A.-M., Nordborg, C., Peterson, D. A., \& Gage, F. H. (1998). Neurogenesis in the adult human hippocampus. Nature Medicine, 4(11), 1313-1317. doi:10.1038/3305

Feldon, D. F. (2007). Cognitive load and classroom teaching: The double-edged sword of automaticity. Educational Psychologist, 42(3), 123-137. doi:10.1080/00461520701416173

Feltovich, P. J., Prietula, M. J., \& Ericsson, K. A. (2006). Studies of expertise from psychological perspectives. The Cambridge Handbook of Expertise and Expert Performance, 41-67. 
Fiorella, L. (2020). The science of habit and its implications for student learning and well-being. Educational Psychology Review. doi:10.1007/s10648-020-09525-1

Forzani, F. M. (2014). Understanding “core practices" and "practice-based" teacher education: Learning from the past. Journal of Teacher Education, 65(4), 357-368.

Friedman, I. A., \& Kass, E. (2002). Teacher self-efficacy: A classroom-organization conceptualization. Teaching and Teacher Education, 18(6), 675-686. doi:10.1016/S0742-051X(02)00027-6

Gable, P. A., Poole, B. D., \& Harmon-Jones, E. (2015). Anger perceptually and conceptually narrows cognitive scope. Journal of Personality and Social Psychology, 109(1), 163-174. doi:10.1037/a0039226

Goldberg, S. B., Del Re, A. C., Hoyt, W. T., \& Davis, J. M. (2014). The secret ingredient in mindfulness interventions? A case for practice quality over quantity. Journal of Counseling Psychology, 61(3), 491. doi:10.1037/cou0000032

Goldberg, S. B., Tucker, R. P., Greene, P. A., Davidson, R. J., Wampold, B. E., Kearney, D. J., \& Simpson, T. L. (2017). Mindfulness-based interventions for psychiatric disorders: A systematic review and meta-analysis.Clinical Psychology Review. doi:10.31231/osf.io/etghn

Goldhaber, D. (2007). Everyone's doing it, but what does teacher testing tell us about teacher effectiveness? Journal of Human Resources,42(4),765-794. doi:10.1037/e722702011-001

Goleman, D., \& Davidson, R. J. (2017). Altered Traits: Science Reveals how Meditation Changes Your Mind, Brain, and Body. Penguin.

Greenberg, J., McKee, A., \& Walsh, K. (2013). Teacher prep review: A review of the nation's teacher preparation programs. National Council on Teacher Quality. 
Greenberg, J., Putman, H., \& Walsh, K. (2014). Training our future teachers: classroom management. Revised. National Council on Teacher Quality.

Gregory, A., Hafen, C. A., Ruzek, E., Mikami, A. Y., Allen, J. P., \& Pianta, R. C. (2016). Closing the racial discipline gap in classrooms by changing teacher practice. School Psychology Review, 45(2), 171-191. doi:10.17105/spr45-2.171-191

Grossman, P., Greenberg, S., Hammerness, K., Cohen, J., Alston, C., \& Brown, M. (2009, April). Development of the protocol for language arts teaching observation (PLATO). In annual meeting of the American Educational Research Association, San Diego, CA.

Grossman, P., Hammerness, K., \& McDonald, M. (2009). Redefining teaching, re-imagining teacher education. Teachers and Teaching: Theory and Practice, 15(2), 273-289. doi:10.1080/13540600902875340

Grossman, P., \& McDonald, M. (2008). Back to the future: Directions for research in teaching and teacher education. American Educational Research Journal, 45(1), 184-205. doi:10.3102/0002831207312906

Hamre, B., Hatfield, B., Pianta, R., \& Jamil, F. (2014). Evidence for general and domain-specific elements of teacher-child interactions: Associations with preschool children's development. Child Development, 85(3), 1257-1274. doi:10.1111/cdev.12184

Hamre, B. K., Pianta, R. C., Burchinal, M., Field, S., LoCasale-Crouch, J., Downer, J. T., Howes, C., LaParo, K., \& Scott-Little, C. (2012). A course on effective teacher-child Interactions: Effects on teacher beliefs, knowledge, and observed practice. American Educational Research Journal, 49(1), 88-123. doi:10.3102/0002831211434596

Hargreaves, A. (1998). The emotional practice of teaching. Teaching and Teacher Education, 14(8), 835-854. doi:10.1016/s0742-051x(98)00025-0 
Heckman, J. J., Stixrud, J., \& Urzua, S. (2006). The effects of cognitive and noncognitive abilities on labor market outcomes and social behavior. National Bureau of Economic Research. doi:10.1086/504455

Hen, M., \& Sharabi-Nov, A. (2014). Teaching the teachers: Emotional intelligence training for teachers. Teaching Education, 25(4), 375-390. doi:10.1080/10476210.2014.908838

Hill, H. C., Blunk, M. L., Charalambous, C. Y., Lewis, J. M., Phelps, G. C., Sleep, L., \& Ball, D. L. (2008). Mathematical knowledge for teaching and the mathematical quality of instruction: An exploratory study. Cognition and Instruction, 26(4), 430-511.

Hodis, F. A., \& Hancock, G. R. (2016). Introduction to the special issue: Advances in quantitative methods to further research in education and educational psychology. Educational Psychologist, 51(3-4), 301-304. doi:10.1080/00461520.2016.1208750

Hojat, M., Mangione, S., Nasca, T. J., Gonnella, J. S., \& Magee, M. (2005). Empathy scores in medical school and ratings of empathic behavior in residency training 3 years later. The Journal of Social Psychology,145(6), 663-672.doi:10.3200/SOCP.145.6.663-672

Hoy, A. W. (2000). Educational psychology in teacher education. Educational Psychologist, 35(4), 257-270. doi:10.1207/S15326985EP3504_04

Jackson, C. K. (2012). Non-cognitive ability, test scores, and teacher quality: Evidence from 9th grade teachers in North Carolina. National Bureau of Economic Research. http://www.nber.org/papers/w18624

Janssen, F., Grossman, P., \& Westbroek, H. (2015). Facilitating decomposition and recomposition in practice-based teacher education: The power of modularity. Teaching and Teacher Education, 51, 137-146. doi:10.1016/j.tate.2015.06.009

Jennings, P. A., Brown, J. L., Frank, J. L., Doyle, S., Oh, Y., Davis, R., Rasheed, D., DeWeese, 
A., DeMauro, A. A., Cham, H., \& Greenberg, M. T. (2017). Impacts of the CARE for teachers program on teachers' social and emotional competence and classroom interactions. Journal of Educational Psychology. doi:10.1037/edu0000187

Jennings, P. A., \& Greenberg, M. T. (2009). The prosocial classroom: Teacher social and emotional competence in relation to student and classroom outcomes. Review of Educational Research, 79(1), 491-525. doi:10.3102/0034654308325693

Kabat-Zinn, J. (2013). Full catastrophe living, revised edition: How to cope with stress, pain and illness using mindfulness meditation. Hachette UK.

Kemeny, M. E., Foltz, C., Cavanagh, J. F., Cullen, M., Giese-Davis, J., Jennings, P., Rosenberg, E. L., Gillath, O., Shaver, P. R., Wallace, B. A., \& Ekman, P. (2012). Contemplative lemotion training reduces negative emotional behavior and promotes prosocial responses. Emotion. 12(2), 338-350. doi:10.1037/a0026118

Kennedy, M. (1999). The role of preservice teacher education. Teaching as the Learning Profession: Handbook of Policy and Practice, 54-85.

Kennedy, M. M. (2016). How does professional development improve teaching? Review of Educational Research. doi:10.3102/0034654315626800

Klusmann, U., Kunter, M., Trautwein, U., Lüdtke, O., \& Baumert, J. (2008). Teachers’ occupational well-being and quality of instruction: The important role of self-regulatory patterns. Journal of Educational Psychology, 100(3), 702. doi:10.1037/00220663.100 .3 .702

Knudsen, E. I., Heckman, J. J., Cameron, J. L., \& Shonkoff, J. P. (2006). Economic, neurobiological, and behavioral perspectives on building America's future workforce. Proceedings of the National Academy of Sciences, 103(27), 10155-10162. 
doi:10.3386/w12298

Kraft, M. A., Blazar, D., \& Hogan, D. (2016). The effect of teacher coaching on instruction and achievement: A meta-analysis of the causal evidence. Review of Educational Research. doi:10.3102/0034654318759268

Kunter, M., Klusmann, U., Baumert, J., Richter, D., Voss, T., \& Hachfeld, A. (2013). Professional competence of teachers: Effects on instructional quality and student development. Journal of Educational Psychology, 105(3), 805.doi.org/10.1037/a0032583

La Paro, K. M., Pianta, R. C., \& Stuhlman, M. (2004). The Classroom Assessment Scoring System: Findings from the prekindergarten year. The Elementary School Journal, 104(5), 409-426. doi:10.1086/499760

Labaree, David F. (2008). An uneasy relationship: The history of teacher education in the university. In M. Cochran-Smith, S.F. Nemser, \& D.J. McIntyre (Eds.), Handbook of research on teacher education: Enduring issues in changing contexts, 3 rd ed. (pp. 290306). Washington, DC: Association of Teacher Educators.

Lampert, M., Beasley, H., Ghousseini, H., Kazemi, E., \& Franke, M. (2010). Using designed instructional activities to enable novices to manage ambitious mathematics teaching. In Instructional explanations in the disciplines (pp. 129-141). Springer.

Loughran, J. (1995). Practicing what I preach: Modelling reflective practice to student teachers. Research in Science Education, 25(4), 431-451.

Luberto, C. M., Shinday, N., Song, R., Philpotts, L. L., Park, E. R., Fricchione, G. L., \& Yeh, G. Y. (2017). A systematic review and meta-analysis of the effects of meditation on empathy, compassion, and prosocial behaviors. Mindfulness, 1-17. doi:10.1007/s12671017-0841-8 
Mansfield, C. F., Beltman, S., Price, A., \& McConney, A. (2012). "Don’t sweat the small stuff:" Understanding teacher resilience at the chalkface. Teaching and Teacher Education, 28(3), 357-367. doi:10.1016/j.tate.2011.11.001

Mayer, J. D., Caruso, D. R., \& Salovey, P. (2016). The ability model of emotional intelligence: Principles and updates. Emotion Review, 8(4), 290-300. doi:10.1177/1754073916639667

McCarthy, C.J. (2019). Teacher stress: Balancing demands and resources. Phi Delta Kappan, 101(3), 8-14.

McDonald, M., Kazemi, E., \& Kavanagh, S. S. (2013). Core practices and pedagogies of teacher education A call for a common language and collective activity. Journal of Teacher Education, 64(5), 378-386. doi:10.1177/0022487113493807

Melby-Lervåg, M., Redick, T. S., \& Hulme, C. (2016). Working memory training does not improve performance on measures of intelligence or other measures of "far transfer" Evidence from a meta-analytic review. Perspectives on Psychological Science, 11(4), 512-534. doi:10.1177/1745691616635612

OECD (2019), TALIS 2018 results (Volume I): Teachers and school leaders as lifelong learners, TALIS, OECD Publishing, Paris, doi:10.1787/1d0bc92a-en.

Office of Head Start (2018). A National Overview of Grantee Class Scores in 2018. Retrieved from eclkc.ohs.acf.hhs.gov/sites/default/files/pdf/no-search/national-class-2018-data.pdf Patrick, H., Anderman, L. H., Bruening, P. S., \& Duffin, L. C. (2011). The role of educational psychology in teacher education: Three challenges for educational psychologists. Educational Psychologist, 46(2), 71-83. doi:10.1080/00461520.2011.538648

PDK International. (2019). Frustration in the schools: PDK poll of the public's attitudes toward the public schools. Arlington, VA. 
Peercy, M. M., \& Troyan, F. J. (2017). Making transparent the challenges of developing a practice-based pedagogy of teacher education. Teaching and Teacher Education, 61, 2636. doi:10.1016/j.tate.2016.10.005

Pelligrino \& Hilton. (2012). Education for life and work: Developing transferable knowledge and skills in the 21st century. National Academies Press.

Pianta, R. C., \& Hamre, B. K. (2009). Conceptualization, measurement, and improvement of classroom processes: Standardized observation can leverage capacity. Educational Researcher, 38(2), 109-119. doi:10.3102/0013189x09332374

Plass, J. L., \& Kalyuga, S. (2019). Four ways of considering emotion in cognitive load theory. Educational Psychology Review. doi:10.1007/s10648-019-09473-5

Putnam, R. T., \& Borko, H. (2000). What do new views of knowledge and thinking have to say about research on teacher learning? Educational Researcher, 29(1), 4-15. doi:10.2307/1176586

Rabinowitz, W., \& Travers, R. M. W. (1953). Problems of defining and assessing teacher effectiveness. Educational Theory, 3, 212-219. doi:10.1111/j.1741-5446.1953.tb01052.x

Rivkin, S. G., Hanushek, E. A., \& Kain, J. F. (2005). Teachers, schools, and academic achievement. Econometrica, 417-458. doi:10.3386/w6691

Roberts, B. W., Luo, J., Briley, D. A., Chow, P. I., Su, R., \& Hill, P. L. (2017). A systematic review of personality trait change through intervention. Psychological Bulletin. doi:10.1037/bul0000088

Robertson-Kraft, C., \& Duckworth, A. L. (2014). True grit: Trait-level perseverance and passion for long-term goals predicts effectiveness and retention among novice teachers. Teachers College Record (1970), 116(3). 
Rockoff, J. E. (2004). The impact of individual teachers on student achievement: Evidence from panel data. The American Economic Review, 94(2), 247-252. doi:10.1257/0002828041302244

Roeser, R. W., Schonert-Reichl, K. A., Jha, A., Cullen, M., Wallace, L., Wilensky, R., Oberle, E., Thomson, K., Taylor, C., \& Harrison, J. (2013). Mindfulness training and reductions in teacher stress and burnout: Results from two randomized, waitlist-control field trials. Journal of Educational Psychology, 105(3), 787-804. doi:10.1037/a0032093

Roeser, R. W., Skinner, E., Beers, J., \& Jennings, P. A. (2012). Mindfulness training and teachers' professional development: An emerging area of research and practice. Child Development Perspectives, 6(2), 167-173. doi:10.1037/a0032093

Ronfeldt, M. (2015). Field placement schools and instructional effectiveness. Journal of Teacher Education, 66(4), 304-320. doi:10.1177/0022487115592463

Roser, M.(2020) - "Teachers and Professors". Retrieved from: https://ourworldindata.org

Sabers, D. S., Cushing, K. S., \& Berliner, D. C. (1991). Differences among teachers in a task characterized by simultaneity, multidimensional, and immediacy. American Educational Research Journal, 28(1), 63-88. doi:10.3102/00028312028001063

Schempp, P., Tan, S., Manross, D., \& Fincher, M. (1998). Differences in novice and competent teachers' knowledge.Teachers and Teaching, 4(1), 9-20. doi:10.1080/1354060980040102

Schonert-Reichl, K. A. (2019). Advancements in the landscape of social and emotional learning and emerging topics on the horizon. Educational Psychologist, 54(3), 222-232. doi:10.1080/00461520.2019.1633925

Schonert-Reichl, K. A., Kitil, M. J., \& Hanson-Peterson, J. (2017). To reach the students, teach the teachers: A national scan of teacher preparation and social \& emotional learning. A 
report prepared for CASEL. Collaborative for academic, social, and emotional learning.

Schooler, J. W. (2002). Re-representing consciousness: Dissociations between experience and meta-consciousness. Trends in Cognitive Sciences, 6(8), 339-344.

Scriven, M. (1994). Duties of the teacher. Journal of Personnel Evaluation in Education, 8(2), 151-184. doi:10.1007/BF00972261

Shankland, R., \& Rosset, E. (2017). Review of brief school-based positive psychological interventions: A taster for teachers and educators. Educational Psychology Review, 29(2), 363-392. doi:10.1007/s10648-016-9357-3

Shapiro, S. L., Carlson, L. E., Astin, J. A., \& Freedman, B. (2006). Mechanisms of mindfulness. Journal of Clinical Psychology, 62(3), 373-386.

Shulman, L. (1987). Knowledge and teaching: Foundations of the new reform. Harvard Educational Review, 57(1), 1-23. doi:10.17763/haer.57.1.j463w79r56455411

Shulman, L. S. (1986). Those who understand: Knowledge growth in teaching. Educational Researcher, 15(2), 4-14. doi:10.3102/0013189x015002004

Shulman, L. S. (2004). The wisdom of practice: Essays on learning, teaching, and learning to teach. San Francisco: Jossey-Bass.

Squire, L. R. (1992). Declarative and nondeclarative memory: Multiple brain systems supporting learning and memory. Journal of Cognitive Neuroscience, 4(3), 232-243.

Stahl, B., \& Goldstein, E. (2010). A mindfulness-based stress reduction workbook. New Harbinger Publications.

Sutton, R. E., Mudrey-Camino, R., \& Knight, C. C. (2009). Teachers' emotion regulation and classroom management. Theory into Practice, 48(2), 130-137. doi:10.1080/00405840902776418 
Toi, M., \& Batson, C. D. (1982). More evidence that empathy is a source of altruistic motivation. Journal of Personality and Social Psychology, 43(2), 281.

Tsui, A. B. M. (2005). Expertise in teaching: Perspectives and issues. In K. Johnson (Ed.), Expertise in Second Language Learning and Teaching (pp. 167-189). Palgrave Macmillan UK. doi:10.1057/9780230523470_9

US Department of Education, Institute for Educational Science. (2018). Digest of Education Statistics, 2016. Retrieved October 2, 2018, from https://nces.ed.gov/programs/digest/d17/tables/dt17_209.10.asp?current=yes

Vago, D. R., \& Silbersweig, D. A. (2012). Self-awareness, self-regulation, and selftranscendence (S-ART): A framework for understanding the neurobiological mechanisms of mindfulness. Frontiers in Human Neuroscience, 6. doi:10.3389/fnhum.2012.00296

Vancouver, J. B., \& Kendall, L. N. (2006). When self-efficacy negatively relates to motivation and performance in a learning context. Journal of Applied Psychology, 91(5), 1146-1153. doi:10.1037/0021-9010.91.5.1146

Weng, H. Y., Fox, A. S., Shackman, A. J., Stodola, D. E., Caldwell, J. Z., Olson, M. C., Rogers, G. M., \& Davidson, R. J. (2013). Compassion training alters altruism and neural responses to suffering. Psychological Science, 24(7), 1171-1180.

Windschitl, M., Thompson, J., Braaten, M., \& Stroupe, D. (2012). Proposing a core set of instructional practices and tools for teachers of science. Science Education, 96(5), 878903. doi:10.1002/sce.21027

Wright, F. W. (1930). The Evolution of the Normal Schools. The Elementary School Journal, 30(5), 363-371.

Yeh, Y.C. (2004). Nurturing reflective teaching during critical-thinking instruction in a computer 
simulation program. Computers \& Education, 42(2), 181-194. doi:10.1016/S03601315(03)00071-X

Yoon, J. (2002). Teacher characteristics as predictors of teacher-student relationships: Stress, negative affect, and self-efficacy. Social Behavior and Personality: An International Journal, 30(5), 485-493.

Zee, M., \& Koomen, H. M. Y. (2016). Teacher self-efficacy and its effects on classroom processes, student academic adjustment, and teacher well-being: A synthesis of 40 years of research. Review of Educational Research, 86(4), 981-1015.

doi:10.3102/0034654315626801

Zeichner, K. (2010). Rethinking the connections between campus courses and field experiences in college-and university-based teacher education. Journal of Teacher Education, 61(12), 89-99. doi.org/10.1177/0022487109347671

Zeichner, K. (2012). The turn once again toward practice-based teacher education. Journal of Teacher Education, 63(5), 376-382. doi:10.1177/0022487112445789 